\title{
Neuromuscular Review Course
}

\section{1: A Webinar Series}

Please join us for our virtual Neuromuscular Review Course. This two-part webinar will be offered on four different Saturday's. These courses offer comprehensive updates in the general diagnostic and lab approaches to neuromuscular disorders, and the presentation and management of specific neuromuscular diseases. There will be ample time for discussion and Q\&A.

\section{Morning Session - Diagnosis and Treatment of Neuropathies}

Afternoon Session - Diagnosis and Treatment of Peripheral Nervous System Motor Disorders

Faculty

Mazen Dimachkie, MD - Course Director, University of Kansas Medical Center

Richard Barohn, MD - University of Missouri Health System

Jonathan Katz, MD - Forbes Norris ALS/MDA Center

Todd Levine, MD - Medical Director of Neurology, Honor Health

We hope that you, your colleagues and your trainees can join us. CME credit will be provided by the University of Kansas Medical Center.

To learn more, see the agendas or register - click on any of the links below. Registration fee is $\$ 25.00$ per session or $\$ 40.00$ for both sessions (if attending on the same day). The agenda times will be targeted toward specific time zones, but you are welcome to participate on any of the dates (please adjust the times to your time zone accordingly).

Saturday, September 25 - Eastern Time Zone www.eeds.com/live/672129

Saturday, November 06 - Central Time Zone www.eeds.com/live/400947

Saturday, November 20 - Pacific Time Zone www.eeds.com/live/187300

Saturday, December 18 - Pacific Time Zone www.eeds.com/live/352183 